\title{
Pengaruh Iklan Terhadap Keputusan Pembelian Produk Smartphone Oppo Di IT Center Manado
}

\author{
Serina O. Moloku \\ Johny R.E Tampi \\ Olivia Walangitan \\ Program Studi Administrasi Bisnis, Jurusan Ilmu Administrasi \\ Fakultas Ilmu Sosial dan Politik. Universitas Sam Ratulangi \\ Orisandymoloku@gmail.com
}

\begin{abstract}
The purpose of this study is to find out whether there is an influence of advertising on the decision to buy oppo smartphone products at the Manado IT Center. The approach of this research is a quantitative approach. The independent variable is advertising and the dependent variable is a purchasing decision. The population in this study were oppo smartphone users in the city of Manado who had bought Oppo smartphone products at the Manado IT Center. The population in this study is infinite. Sampling uses probability sampling. The sampling technique uses incidental sampling techniques. The total sample of respondents is 100 people. The method of data collection is through questionnaires, observation and documentation. The research instrument uses a Likert scale. Test instruments used validity test and reliability test. Data analysis used using simple linear regression analysis. Data processing is used by the SPSS 25 program. The results of the study are obtained is the value of the coefficient between advertising and purchasing decisions including low of 0.394, The effect of advertising on purchasing decisions is very low at 0.1555 and the results of simple linear regression analysis obtained a positive regression coeficient so that the direction of the influence of advertising variables on the variable buying decision is positive.
\end{abstract}

Keywords: Advertising, Buying Decision

\section{Pendahuluan}

Saat ini di Indonesia terdapat banyak perusahaan elektronik ternama seperti Samsung, Apple, Lenovo, Oppo, Asus, Nokia, Blackberry, Advan, Xiaomi dan beberapa merek lainnya yang saling berkompetisi memperebutkan pangsa pasar dengan menawarkan harga yang bervariatif dan tentunya menggunakan strategi promosi yang mumpuni agar produk yang mereka jual lebih di kenal oleh masyarakat sehingga mereka mau membelinya.
Promosi yang dilakukan pun beragam mulai dengan memberikan cashback, menggunakan brand ambassador dan membuat iklan yang unik di berbagai media cetak maupun online sehingga biaya yang dikeluarkan pun tidak sedikit.

Salah satu smartphone yang saat ini tengah populer di masyarakat yaitu Oppo. Oppo merupakan smartphone asal Tiongkok yang memasuki pasar Indonesia pada tahun 2013 dengan produknya Opppo Find 5 dan ternyata smartphone Oppo 
diterima begitu baik oleh masyarakat karena menawarkan harga yang murah dengan kualitas produk yang mumpuni. Kini, memasuki tahun keenam berada di pasar Indonesia Oppo telah mengeluarkan berbagai macam tipe smartphone mereka diantaranya yaitu Oppo F1s, Oppo F1s Plus, Oppo F3 Selfie Expert, Oppo F5, Oppo F7, Oppo A57, Oppo A37, Oppo Find X, Oppo A3S, Oppo F9. Guna memperkenalkan produk mereka, Oppo gencar melakukan promosi dengan memasang iklan di berbagai media, menggunakan artis top indonesia untuk menjadi brand ambassador mereka, dan menjadi sponsorhip berbagai acara di televisi. Demi mempromosikan produk mereka, Oppo mengeluarkan biaya yang tak sedikit. Berdasarkan data dari perusahaan riset Nielsen Indonesia pada 18 april 2018, mencatat nilai total belanja iklan telepon pintar (smartphone) di Indonesia mencapai $\mathrm{Rp} \mathrm{3,2} \mathrm{triliun.} \mathrm{Oppo}$ menduduki posisi ketiga dengan menghabiskan biaya Rp 461 miliar,. Oppo lebih banyak menghabiskan biaya iklan dalam bentuk in-program ads ketimbang commercial break. Berdasarkan data dari IDC (Internasional Data Corporation) di Indonesia pada kuartal ketiga 2018 terkait pasar smartphone di Indonesia, Samsung menduduki posisi pertama dan sepanjang juli hingga september 2018, Samsung menguasai $28 \%$ pasar. Di posisi selanjutnya ada Xiaomi yang menguasai pasar 24\%, Oppo yang menguasai pasar 19\%, Vivo yang menguasai pasar $11 \%$, Advan yang menguasai pasar 5\%, dan $13 \%$ di kuasai oleh merek-merek lain.

Diketahui bahwa perusahaan Oppo Indonesia telah mengeluarkan biaya yang tidak sedikit dalam mempromosikan produk smartphone mereka namun hanya bisa menguasai $19 \%$ pasar di Indonesia. Di Kota Manado, salah satu tempat pembelanjaan smartphone yang telah dikenal luas oleh masyarakat adalah IT Center Manado yang terletak di jl. Pierre Tenden, Boulevard Wenang Sulawesi Utara 95111. Berdiri sejak tahun 2007, kini IT Center Manado telah dipenuhi dengan berbagai macam merek dan tipe smartphone yang memiliki gerai-gerainya tersendiri diantaranya adalah Samsung, Oppo, Vivo, Xiaomi, Blackberry, Asus, Smartfren, Apple, dan lain-lain.

\section{Periklanan}

American Marketing Association (AMA) dalam Malau (2017:85) mendefinisikan iklan sebagai semua bentuk bayaran untuk mempresentasikan dan mempromosikan ide barang atau jsa secara non perseonal oleh sponsor yang jelas.

Kotler dan Keller (2016:528), adversiting is any paid from nonpersonal presentation and promotion of ideas, goods or services by an indetified sponsor atau iklan adalah segala bentuk komunikasi nonpersonal dan promosi gagasan, produk, atau jasa yang dibayarkan oleh sponsor tertentu atau yang diketahui.

Indikator-indikator yang dapat digunakan untuk mengukur variabel 
periklanan menurut Kotler dan Armstrong (2008:157) sebagai berikut :

1. Penemuan informasi tentang produk atau perusahaan dari berbagai media mudah.

2. Design media yang digunakan menarik.

3. Informasi yang disampaikan dalam berbagai media jelas.

4. Pesan yang terkandung dalam berbagai media dapat di percaya.

\section{Fungsi Iklan}

Menurut Tjiptono dalam Malau (2017:85) mengatakan bahwa iklan memilki empat fungsi utama yaitu :

1) Menginformasikan khalayak mengenai seluk beluk produk (informative.,

2) Mempengaruhi khalayak untuk membeli (persuading).

3) Menyegarkan informasi yang telah di terima khlayak (reminding).

4) Menciptakan suasana yang menyenangkan sewaktu khalayak menerima dan mencerna informasi (entertainment).

\section{Keputusan Pembelian}

Kotler dalam jurnal Elisa,Firdaus (2015), keputusan pembelian adalah suatu keputusan yang dilakukan oleh konsumen, baik konsumen individu maupun pembeli organisasi melalui proses mental yang hampir sama dalam memutuskan produk dan merek apa yang akan dibeli. Keputusan pembelian adalah seleksi terhadap dua pilihan alternatif konsumen pada pembelian (Schiffman dan Kanuk dalam jurnal Asri Fajar 2015),
Kotler dan Keller dalam jurnal Pradnya (2015) mengatakan, ada enam indikator keputusan pembelian, yaitu:

1. Pemilihan Produk

Konsumen menentukan produk mana yang akan dibeli, konsumen akan membeli produk yang memiliki nilai baginya.

2. Pemilihan Merek

Konsumen harus menentukan merek mana yang akan dibeli, setiap merek memilikiperbedaan-perbedaan tersendiri.

3. Pemilihan Saluran Pembelian

Konsumen harus mengambil keputusan tentang penyalur mana yang akan dikunjungi.

4. Penentuan Waktu Pembelian

Keputusan konsumen dalam pemilihan waktu pembelian dapat berbeda-beda.

5. Jumlah Pembelian

Konsumen dapat mengambil keputusan tentang seberapa banyak produk yang akan dibelinya pada suatu saat.

6. Metode Pembayaran

Konsumen dapat mengambil keputusan tentang metode pembayaran yang akan dilakukan dalam pengambilan keputusan konsumen menggunakan produk atau jasa.

\section{Proses Pengambilan Keputusan \\ Pembelian}

Malau (2017:236) mengemukakan langkah-langkah dari proses pengambilan keputusan yaitu : 
1. Membutuhkan Pengakuan

Proses pembelian dimulai dengan pengenalan kebutuhan-pembeli mengakui ada masalah atau kebutuhan. Kebutuhan dapat dipicu stimulus internal dan juga oleh rangsangan eksternal.

\section{Pencarian Informasi}

Konsumen yang tertarik mungkin atau mungkin tidak mencari informasi lebih lanjut. Jika dorongan konsumen kuat dan produk yang memuaskan berada dekat, ia cenderung untuk membelinya kemudian.

3. Mengevaluasi Alternatif

Bagaimana konsumen berlanjut untuk mengevaluasi alternatif pembelian tergantung pada konsumen individual dan situasi pembelian tertentu.

\section{Keputusan Pembelian}

Umumnya, keputusan pembelian akan membeli merek yang paling disukai, tetapi dua faktor bisa datang antara niat pembelian dan keputusan pembelian. Faktor pertama adalah sikap orang lain dan faktor kedua adalah faktor situasional yang tak terduga.

\section{Perilaku Pasca Pembelian}

Setelah membeli produk, konsumen akan baik puas atau tidak puas dan akan terlibat dalam perilaku pasca pembelian yang menarik bagi pemasar

\section{Metode Penelitian}

Pendekatan dalam penelitian ini menggunakan pendekatan kuantitatif. Populasi dalam penelitian ialah pengguna smartphone Oppo yang membeli smartphone mereka di IT Center Manado yang jumlahnya tidak dapat diketahui dan masuk dalam kategori populasi tak terhingga. Sampel yang digunakan dalam penelitian ini sebanyak 100 responden. Penentuan pengambilan sampel menggunakan probability sampling dengan teknik insidental sampling. Teknik pengumpulan data menggunakan kuesioner, wawancara dan dokumentasi. Instrumen penelitian menggunakan skala likert, uji instrumen penelitian menggunakan uji validitas dan uji reabilitas dan analisis data menggunakan analisis regresi linier sederhana.

\section{Hasil Penelitian}

Analisis Uji Instrumen Penelitian

a. Uji Validitas Variabel Iklan

\begin{tabular}{cccc}
\hline Item & $\begin{array}{c}\text { Nilai } \\
\text { Korelasi }\end{array}$ & $\begin{array}{c}\text { Nilai R } \\
\text { Tabel }\end{array}$ & Status \\
\hline $\mathbf{1}$ & 0,326 & 0,195 & Valid \\
\hline $\mathbf{2}$ & 0,623 & 0,195 & Valid \\
\hline $\mathbf{3}$ & 0,666 & 0,195 & Valid \\
\hline $\mathbf{4}$ & 0,631 & 0,195 & Valid \\
\hline $\mathbf{5}$ & 0,403 & 0,195 & Valid \\
\hline $\mathbf{6}$ & 0,507 & 0,195 & Valid \\
\hline $\mathbf{7}$ & 0,478 & 0,195 & Valid \\
\hline $\mathbf{8}$ & 0,541 & 0,195 & Valid \\
\hline
\end{tabular}

Sumber : Hasil dari olah data, 2019

Diketahui bahwa semua pernyataan tentang iklan (variabel $\mathrm{x}$ ) dikatakan valid. Hal tersebut dikarenakan dari nilai $r_{\text {hitung }}>\quad r_{\text {tabel }} \quad(0,195) \quad$ sehingga dinyatakan bahwa semua pernyataan di kuesioner dapat digunakan pada penelitian. 


\section{b. Uji Validitas Variabel Keputusan Pembelian}

\begin{tabular}{cccc}
\hline Item & $\begin{array}{c}\text { Nilai } \\
\text { Korelasi }\end{array}$ & $\begin{array}{c}\text { Nilai R } \\
\text { Tabel }\end{array}$ & Status \\
\hline $\mathbf{1}$ & 0,496 & 0,195 & Valid \\
\hline $\mathbf{2}$ & 0,510 & 0,195 & Valid \\
\hline $\mathbf{3}$ & 0,488 & 0,195 & Valid \\
\hline $\mathbf{4}$ & 0,489 & 0,195 & Valid \\
\hline $\mathbf{5}$ & 0,440 & 0,195 & Valid \\
\hline $\mathbf{6}$ & 0,523 & 0,195 & Valid \\
\hline
\end{tabular}

Sumber : Hasil dari olah data, 2019

Diketahui bahwa semua pernyatan tentang keputusan pembelian (variabel y) dikatakan valid. Hal tersebut dikarenakan dari nilai $r_{\text {hitung }}>r_{\text {tabel }}(0,195)$ sehingga dinyatakan bahwa semua pernyataan di kuesioner dapat digunakan pada penelitian.

\section{c. Uji Reabilitas Variabel}

Variabel Cronbach Keterangan Alpha

\begin{tabular}{ccc}
\hline Iklan & 0,712 & Reliable \\
\hline $\begin{array}{l}\text { Keputusan } \\
\text { Pembelian }\end{array}$ & 0,666 & Reliable \\
\hline
\end{tabular}

Sumber : Hasil dari olah data, 2019

Dapat dilihat hasil dari cronbach alpha untuk kedua variabel lebih besar dari $r_{\text {tabel }}(0,195)$ sehingga pernyataan kuesioner dapat digunakan karena reliable atau konsisten.

\section{Analisis Koefisien Korelasi dan Determinasi}

\begin{tabular}{ll|r|r|r} 
& & & \multicolumn{2}{c}{ Model Summary } \\
$\begin{array}{l}\text { Mod } \\
\text { el }\end{array}$ & $\mathrm{R}$ & $\begin{array}{c}\text { R } \\
\text { Square }\end{array}$ & $\begin{array}{c}\text { Adjusted } \\
\text { R Square }\end{array}$ & $\begin{array}{c}\text { Estimate } \\
\text { of the }\end{array}$ \\
\hline 1 & $.394^{\mathrm{a}}$ & .155 & .147 & 2.85858 \\
\hline
\end{tabular}

a. Predictors: (Constant), iklan

b. Dependent Variabel: keputusan pembelian Sumber : Hasil dari olah data, 2019

Diketahui bahwa nilai koefisien korelasi atau $\mathrm{R}$ sebesar 0,394. Hubungan antara iklan terhadap keputusan pembelian dikatakan rendah yaitu sebesar $39,4 \%$. Hal tersebut diketahui dari tabel berikut:

\begin{tabular}{cc}
\hline Koefisien Korelasi & Tingkat Hubungan \\
\hline $\mathbf{0 , 0 0}-\mathbf{0 , 1 9 9}$ & Sangat Rendah \\
\hline $\mathbf{0 , 2 0}-\mathbf{0 , 3 9 9}$ & Rendah \\
\hline $\mathbf{0 , 4 0}-\mathbf{0 , 5 9 9}$ & Sedang \\
\hline $\mathbf{0 , 6 0}-\mathbf{0 , 6 9 9}$ & Kuat \\
\hline $\mathbf{0 , 8 0}-\mathbf{1 , 0 0 0}$ & Sangat Kuat \\
\hline
\end{tabular}

Sumber : Sugiyono 2014

Diketahui juga hasil koefisien determinasi ( $\mathrm{R}$ square) adalah 0,155. Berdasarkan angka tersebut menunjukkan bahwa 15,5\% keputusan pembelian dipengaruhi oleh iklan sementara sisanya $84,5 \%$ dipengaruhi oleh variabel lain yang tidak diteliti dalam penelitian ini seperti harga, kualitas pelayanan, lokasi dan lain-lain.

\section{Analisis Regresi Linier Sederhana}

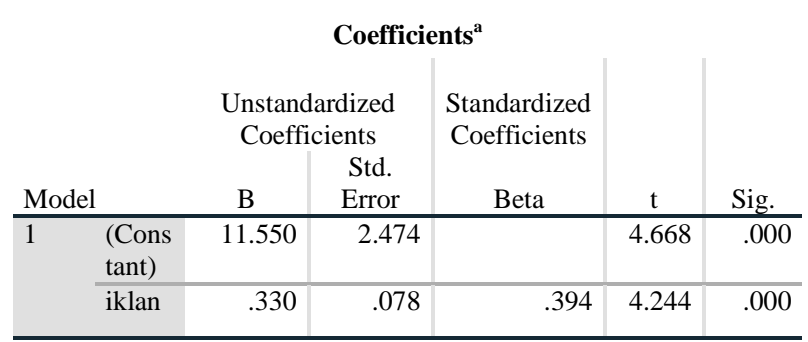

a. Dependent Variable: keputusan pembelian

Sumber: Olah datA SPSS 25

Maka diketahui persamaan regresi linier sederhana dalam penelitian ini yaitu :

$$
\mathrm{Y}=11,550+0,330 \mathrm{X}
$$


Konstanta sebesar 11,550 berarti bahwa nilai konstanta variabel keputusan pembelian adalah sebesar 11,550. Koefisien regresi variabel $\mathrm{X}$ sebesar 0,330 artinya bahwa setiap penambahan $1 \%$ nilai iklan maka nilai keputusan pembelian bertambah sebesar 0,330. Koefisien regresi tersebut bernilai positif sehinga dapat dikatakan bahwa arah pengaruh variabel $\mathrm{X}$ terhadap variabel $Y$ adalah positif.

Diperoleh juga nilai $T_{\text {hitung }}$ untuk variabel iklan adalah 4,244 dan signifikansi sebesar 0,000. Nilai $T_{\text {tabel }}$ adalah 1,984. Dapat diketahui bahwa nilai $T_{\text {hitung }}>$ $T_{\text {tabel }}$ yaitu 4,244 lebih besar dari 1,984.

\section{Pembahasan}

Dari hasil penelitian, jumlah responden perempuan lebih banyak dibandingkan jumlah responden laki-laki yaitu sebesar $70 \%$. Yang menjadi responden didominasi oleh mahasiswa sebanyak 55\%. Rentan usia responden 15 sampai 20 tahun lebih banyak lebih banyak bila dibandingkan dengan rentan usia lainnya yaitu sebesar $63 \%$.

Dari hasil penelitian diketahui bahwa empat indikator iklan yang digunakan untuk penelitian mendapatkan tanggapan positif dari responden. sebanyak $74 \%$ responden telah melihat iklan smartphone oppo di berbagai media, ini berarti penempatan iklan berada di tempat yang tepat sehingga dapat menjangkau masyarakat. $79 \%$ responden menyetujui kalau informasi tentang smartphone oppo mudah ditemui diberbagai media, berarti informasi tentang smartphone Oppo seperti harga, atribut produk, tempat penjualan, dll dapat dengan mudah ditemui sehingga masyarakat dapat mengetahui tentang produk smartphone Oppo. 73\% responden menyetujui kalau desain informasi tentang smartphone oppo di media cetak atau online sangat menarik, berarti penggunaan desain yang inovatif serta edukatif yang secara tidak langsung membuat masyarakat menjadi tertarik untuk melihat iklan smartphone Oppo di media cetak atau online berhasil di lakukan Oppo Indonesia. $82 \%$ responden menyetujui informasi tentang smartphone oppo di media cetak atau online begitu jelas, artinya bahwa penggunaan kalimat disetiap iklan smartphone Oppo yang ada di media cetak dan online begitu tepat. $79 \%$ responden telah memahami informasi tentang smartphone oppo diberbagai media artinya penggunaan kalimat yang digunakan di media cetak ataupun online dapat membuat masyarakat memahaminya didukung dengan desain yang inovatf dan edukatif . $56 \%$ responden mempercayai informasi smartphone oppo yang ada di media cetak artinya dikarenakan pengampaian melalui media cetak saat ini kurang dilirik oleh masyarakat membuat hanya $56 \%$ responden saja yang memahaminya. 69\% responden mempercayai informasi smartphone oppo di media online, kini penyampaian informasi melalui media online memang dapat membuat masyarakat lebih memahaminya ketimbang dimedia cetak.

Untuk variabel keputusan pembelian di peroleh enam pernyataan pada kuesioner yang berlandaskan dari indikator penelitian yang digunakan. Sebanyak $80 \%$ responden 
membeli smartphone oppo karena kebutuhan ini. $75 \%$ responden membeli smartphone oppo karena merupakan salah satu merek smartphone ternama di Indonesia. $58 \%$ responden membeli smartphone oppo di gerai resmi yang ada di IT Center Manado artinya masih ada masyarakat yang memilih untuk membeli smartphone Oppo di gerai yang tidak resmi ataupun secara online . 49\% responden membeli smartphone oppo ketika mempunyai uang, smartphone saat ini menjadi kebutuhan primer seiring berkembangnya zaman dan ini membuat masyarakat memaksakan untuk memiliki smartphone biarpun mereka belum memiliki uang. $42 \%$ responden hanya membeli satu smartphone oppo dalam sekali belanja arinya lebih dari setangah membeli smartphone Oppo lebih dari satu dalam sekali belanja. 59\% responden membeli smartphone oppo dengan pembayaran cash/tunai.

Berdasarkan hasil analisis data, diketahui bahwa pengaruh iklan dalam keputusan pembelian produk smartphone Oppo di IT Center Manado termasuk dalam kategori sangat rendah yaitu hanya $15,5 \%$. Ini membuktikan kalau iklan yang ada di berbagai media cetak ataupun online yang menjadi salah satu cara untuk mempromosikan produk smartphone oppo sebagaimana menurut Kotler dan Keller (2016:528) iklan adalah segala bentuk komunikasi nonpersonal dan promosi gagasan, produk, atau jasa yan dibayarkan oleh sponsor tertentu atau yang diketahui, ternyata memiliki pengaruh yang sangat rendah dalam setiap keputusan pembelian produk smartphone Oppo di IT Center Manado karena dalam membuat keputusan pembelian konsumen harus melalui proses mental sebagaimana menurut Kotler dalam jurnal Elisa,Firdaus (2015), keputusan pembelian adalah suatu keputusan yang dilakukan oleh konsumen, baik konsumen individu maupun pembeli organisasi melalui proses mental yang hampir sama dalam memutuskan produk dan merek apa yang akan dibeli. Dan sebanyak 84,5\% dipengaruhi oleh variabel atau faktor yang tidak diteliti dalam penelitian ini seperti harga, kualitas produk, kualitas layanan dan lain-lain. Setelah dilakukan analisis data menggunakan SPSS 25 diperoleh juga nilai koefisien korelasi sebesar 0,394 yang berarti hubungan antara iklan dan keputusan pembelian termasuk di dalam kategori rendah karena hanya diperoleh 39,4\%. Berarti iklan memiliki hubungan yang rendah dengan keputusan pembelian produk smartphone Oppo di IT Center Manado dan biarpun memiliki hubungan yang rendah, iklan tetap dibutuhkan untuk mempromosikan produk agar dapat menjangkau masyarakat.

Pada persamaan regresi sederhana diperoleh koefisien regresi variabel $\mathrm{X}$ sebesar 0,330 artinya bahwa setiap penambahan $1 \%$ nilai iklan maka nilai keputusan pembelian bertambah sebesar 0,330. Diketahui nilai a sebesar 11,550 artinya bahkan jika produsen tidak mempromosikan produk smartphone Oppo dengan tepat dan baik, konsumen akan tetap melakukan pembelian produk 
smartphone Oppo bernilai 11,55 unit . Koefisien regresi tersebut bernilai positif sehingga dapat dikatakan bahwa arah pengaruh variabel $\mathrm{X}$ terhadap variabel $\mathrm{Y}$ adalah positif. Semakin positif hubungan antara iklan dan keputusan pembelian, semakin baik iklan maka semakin meningkat keputusan pembelian, dikatakan berpengaruh positif karena nilai dari $\mathrm{X}$ yaitu 0,330 . Nilai $b$ yaitu 0,330 artinya bahwa setiap penambahan $1 \%$ nilai iklan maka nilai keputusan pembelian bertambah sebesar 0,330 .

\section{Kesimpulan}

Berdasarkan hasil penelitian yang di dapat, dapat disimpulkan sebagai berikut:

Hubungan antara variabel iklan (X) dan variabel keputusan pembelian (Y) termasuk dalam golongan rendah dilihat dari tabel koefisien dan pengaruh dari iklan terhadap keputusan pembelian produk smartphone oppo di IT Center Manado sangat rendah terdapat variabel atau faktor lain yang memiliki hubungan dan pengaruh yang lebih besar dalam keputusan pembelian yang tidak diteliti di dalam penelitian ini seperti harga, kualitas produk, lokasi, kualitas pelayan dan lain-lain.

Berdasarakan hasil dari analisis regresi linier sederhana di peroleh nilai koefisien regresi yang positif, dapat dikatakan bahwa arah pengaruh variabel iklan terhadap variabel keputusan pembelian adalah positif.

\section{Saran}

Berdasarkan hasil penelitian, saransaran yang dapat penulis berikan adalah sebagai berikut :

Setelah diperoleh nilai hubungan dan pengaruh antara variabel iklan dan variabel keputusan pembelian yang rendah dan sangat rendah diharapakan peneliti selanjutnya akan meniliti tentang faktor atau variabel lainnya yang mempunyai hubungan yang lebih besar atau tinggi terhadap keputusan pembelian agar dapat digunakan sebagai salah satu bahan acuan dikemudian hari.

Diharapkan iklan yang di buat oleh Oppo Indonesia kedepannya akan lebih inovatif dan krestif lagi dalam memperkenalkan prduk mereka sehingga iklan tersebut akan menjadi salah satu faktor yang dominan dalam mempengaruhi keputusan pembelian produk smartphone Oppo dikemudian hari dan tentunya agar bisa meningkatkan pangsa pasar di Indonesia.

\section{Daftar Pustaka}

Elisa dan Y. Firdaus. 2015. Pengaruh Iklan Terhadap Keputusan Pembelian Sabun Lifebuoy. Jurnal Manajemen dan Bisnis Sriwijaya Vol 13 No.3

Harman Malau. 2017. Manajemen Pemasaran. Bandung: Alfabeta.

Kotler dan Armstrong. 2008. Prinsipprinsip Pemasaran. Jilid 1 dan 2. Edisi 12. Jakarta: Erlangga.

Kotler, Philip and Kevin Lane Keller. 2016. Marketing Manajemen. 15th Edition. New Jersey: Pearson Pretice Hall 
Razan, Pradnya. 2015. Pengaruh Kualitas Produk, Harga, dan Kepercayaan

Terhadap Proses Keputusan Pembelian Produk Wall Sticker di Online Shop W Store.

Sugiyono, 2014. Metode Penelitian Kuantitatif dilengkapi dengan perbandingan perhitungan manual dan SPSS. Jakarta: Kencana.

Fajar, S.A, Leonardo, B, Aziz F. 2015. Pengaruh Harga, Kualitas Produk dan Promosi Terhadap Keputusan Pembelian Lemari ES Merek LG di PT. Global Elektronik Banyumanik Semarang. Journal of Management Vol 1 No 1. 